\title{
Nucleus-Cytoskeleton Crosstalk During Mitotic Entry
}

\author{
Margarida Dantas ${ }^{1,2,3 t}$, Joana T. Lima ${ }^{1,4 t}$ and Jorge G. Ferreira ${ }^{1,4 *}$ \\ ${ }^{1}$ Instituto de Investigação e Inovação em Saúde - i3S, University of Porto, Porto, Portugal, ${ }^{2}$ BiotechHealth Ph.D. \\ Programme, University of Porto, Porto, Portugal, ${ }^{3}$ Instituto de Ciências Biomédicas Abel Salazar (ICBAS), University of \\ Porto, Porto, Portugal, ${ }^{4}$ Departamento de Biomedicina, Faculdade de Medicina, University of Porto, Porto, Portugal
}

\section{OPEN ACCESS}

Edited by: Anne Straube,

University of Warwick, United Kingdom

Reviewed by: Paola Vagnarelli,

Brunel University London, United Kingdom

Manuel Mendoza

INSERM U964 Institut de Génétique et de Biologie Moléculaire et Cellulaire (IGBMC), France

Ulrike Kutay,

ETH Zürich, Switzerland

*Correspondence: Jorge G. Ferreira

jferreir@ibmc.up.pt

t These authors have contributed equally to this work

Specialty section:

This article was submitted to Cell Growth and Division,

a section of the journal Frontiers in Cell and Developmental Biology

Received: 05 January 2021 Accepted: 26 February 2021 Published: 18 March 2021

Citation:

Dantas M, Lima JT and Ferreira JG (2021) Nucleus-Cytoskeleton Crosstalk

During Mitotic Entry. Front. Cell Dev. Biol. 9:649899. doi: $10.3389 /$ fcell.2021.649899
In preparation for mitosis, cells undergo extensive reorganization of the cytoskeleton and nucleus, so that chromosomes can be efficiently segregated into two daughter cells. Coordination of these cytoskeletal and nuclear events occurs through biochemical regulatory pathways, orchestrated by Cyclin-CDK activity. However, recent studies provide evidence that physical forces are also involved in the early steps of spindle assembly. Here, we will review how the crosstalk of physical forces and biochemical signals coordinates nuclear and cytoplasmic events during the G2-M transition, to ensure efficient spindle assembly and faithful chromosome segregation.

Keywords: mitosis, nucleus, cytoskeleton, centrosome, mechanotransduction, chromosome, nuclear lamina

\section{INTRODUCTION}

An efficient mitosis is required to maintain genomic stability and ensure correct tissue development and homeostasis. While nuclear envelope breakdown (NEB) marks the irreversible step of mitotic commitment, the process starts well before, as chromosomes condense (Antonin and Neumann, 2016) and centrosomes separate (Whitehead et al., 1996). This occurs simultaneously with a global reorganization of the microtubule and actin cytoskeletons. Accordingly, the interphase microtubule cytoskeleton disassembles (Mchedlishvili et al., 2018) and overall microtubule dynamics change (Zhai et al., 1996), which allows the formation of a bipolar spindle (Heald and Khodjakov, 2015) required for accurate chromosome capture (Figure 1). At the same time, the interphase actin cytoskeleton is replaced with a mitotic actomyosin network that is connected with the plasma membrane (Chugh and Paluch, 2018) and drives mitotic rounding (Rosa et al., 2015). Importantly, timely progression through these steps requires the activity of mitotic kinases such as CDK1 and PLK1 (Gavet and Pines, 2010b; Ramanathan et al., 2015; Gheghiani et al., 2017). Simultaneously, within the nucleus, a cascade of events regulated by the same mitotic kinases initiate chromosome condensation (Abe et al., 2011) and trigger disassembly of the nuclear pore complex (NPC; Linder et al., 2017) and nuclear lamina (NL; Heald and McKeon, 1990; Peter et al., 1990).

Here, we will discuss how the interactions between the cytoskeleton and nucleus set the stage for spindle assembly and how the prophase nucleus acts as more than a passive player to ensure a successful mitosis.

\section{MITOTIC CELL ROUNDING}

Mitotic cell rounding is a feature of a large number of eukaryotic cells that lack a cell wall (Mitchison, 1992; Gibson et al., 2006; Thery and Bornens, 2008). However, this is not a universal characteristic, as some metazoan cells such as Ptk1 or newt pneumocytes are still 
A
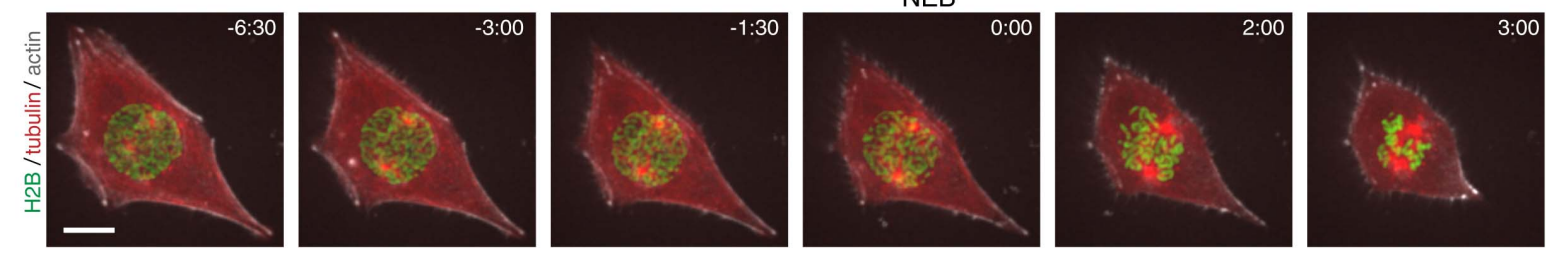

B
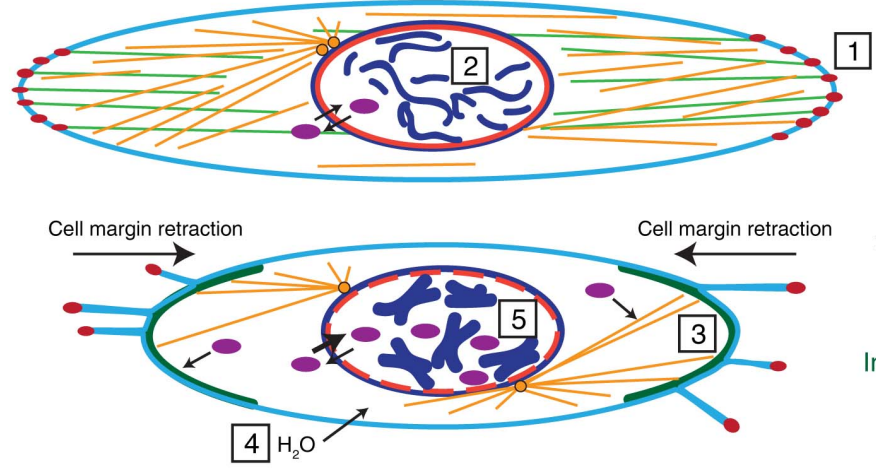

3.Cortical recruitment of actin and myosin 4.Water influx
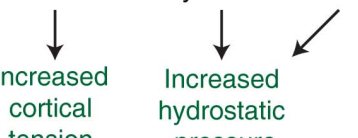

tension
Cytoplasm

1.FA disassembly<smiles>CCC</smiles>

Decrease in
I Nucleus

2.Chromosome condensation

$\mid$

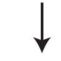

Increased nuclear stiffness

|

5.Nuclear lamina depolymerization

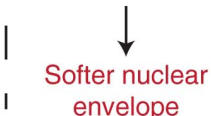

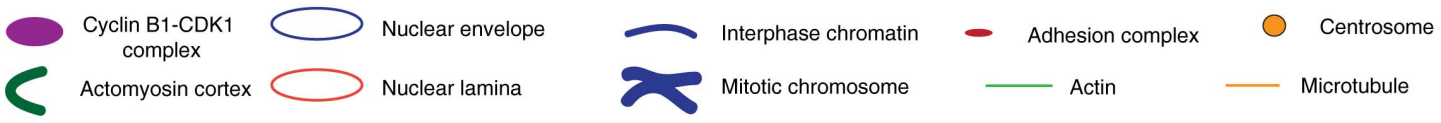

FIGURE 1 | Overview of the cytoskeletal and nuclear reorganization that occur during mitotic entry. (A) Representative frames from a movie of a RPE-1 cell expressing H2B-GFP/tubulin-RFP/SiR-actin during mitotic entry. It is possible to observe the main events that occur during mitotic entry, such as cell rounding, chromosome condensation, and centrosome separation. After NEB, mitotic rounding continues as the spindle assembles. Time is in min:sec. Scale bar, $10 \mu \mathrm{m}$. Time zero corresponds to NEB. (B) Main events that occur during the G2-M transition. Cyclin B1-CDK1 complexes shuttle between the cytoplasm and the nucleus. At this stage, the cell is attached to the extracellular matrix through membrane-bound adhesion complexes (1) and the microtubule and actin cytoskeletons are in their interphase configuration. Inside the nucleus, chromatin is decondensed and the nuclear envelope and nuclear lamina are intact (2). As cells prepare to enter mitosis, adhesion complexes disassemble, leading to cell membrane retraction and mitotic cortex assembly (3). Together with osmotic swelling (4), this leads to increased intracellular pressure. At the same time, active cyclin B1-CDK1 complexes accumulate in the nucleus, triggering chromosome condensation, nuclear lamina depolymerization (5), and nuclear envelope permeabilization. These events trigger changes global changes in the forces during the G2-M transition.

capable of progressing through mitosis without rounding (Roos, 1973; Hayden et al., 1990; Rieder and Alexander, 1990). The rounding process is regulated by CDK1 activity (Jones et al., 2018) and starts in the early stages of mitosis (Matthews et al., 2012) with the loss of Arp2/3-dependent lamellipodia (Bovellan et al., 2014) and disassembly of focal adhesions (FAs; Dao et al., 2009). This loss of FAs leads to the decrease in cell traction forces observed during G2 (Uroz et al., 2018; Vianay et al., 2018) and prophase (Nunes et al., 2020) and allows cell margin retraction (Mitchison, 1992; Maddox and Burridge, 2003) (Figure 1). In turn, this change in cell shape enables the formation of a stiff actomyosin cortex (Maddox and Burridge, 2003; Kunda et al., 2008; Fischer-Friedrich et al., 2016), through the CDK1-mediated phosphorylation of Myosin II (Ramanathan et al., 2015) and Ect2, a RhoGEF that activates the RhoA GTPase (Matthews et al., 2012). In combination with an increase in hydrostatic pressure (Stewart et al., 2011) and cell volume (Zlotek-Zlotkiewicz et al., 2015), likely driven by water influx (Son et al., 2015), these changes provide the necessary space for mitotic spindle assembly and accurate chromosome capture (Kunda et al., 2008; Lancaster et al., 2013). Consequently, a failure in mitotic cell rounding triggered by either blocking FA disassembly or mechanical compression leads to defects in spindle assembly and mitotic progression (Lancaster et al., 2013; Nunes et al., 2020) and increases chromosome missegregation (Tse et al., 2012; Lancaster et al., 2013; Cattin et al., 2015; Matthews et al., 2020). The need for cell rounding was further emphasized with the proposal of an "adhesion-dependent checkpoint," which acts through DEPDC1B to inhibit RhoA activation and allow FA dismantling during the G2-M transition (Marchesi et al., 2014), required for normal proliferation and development of zebrafish embryos.

\section{CENTROSOME SEPARATION AND SPINDLE ASSEMBLY}

In animal cells, spindle assembly originates mainly from the centrosomes. For this reason, many studies have focused on centrosome behavior during the early stages of mitosis. 
Initial centrosome separation requires the combined action of microtubule-associated molecular motors such as kinesin5 and dynein (for review, see Tanenbaum and Medema, 2010). The plus-end directed kinesin-5 has a homo-tetrameric structure that can crosslink and slide anti-parallel microtubules apart (Kashina et al., 1996). This generates pushing forces on microtubules that lead to centrosome separation (Whitehead et al., 1996). For this reason, kinesin-5 has been involved in spindle assembly in nearly all model systems analyzed (Sawin et al., 1992; Heck et al., 1993; Blangy et al., 1995), with the exception of C. elegans (Bishop et al., 2005). Dynein, on the other hand is a microtubule minus-end directed motor (Roberts et al., 2013). To generate the pulling forces necessary for centrosome separation, dynein needs to be tethered to subcellular structures such as the nuclear envelope (NE; Splinter et al., 2010; Bolhy et al., 2011; Nunes et al., 2020) or the cell cortex (Kotak et al., 2012). The combined activity of these motors is sufficient to drive centrosome separation, but it does not explain the biased movement of centrosomes to the shortest axis of the nucleus (Magidson et al., 2011; Nunes et al., 2020). Such a bias would require additional cues (either external or internal) or an asymmetry in the forces exerted on the centrosomes, to direct centrosome movement. Notwithstanding, the extent of centrosome separation, as well as their positioning at the moment of NEB, remain major contributors to chromosome missegregation events. Failure to fully separate centrosomes during mitotic entry can contribute to deviant spindle morphologies (Silkworth et al., 2012; Nam et al., 2015), increasing the likelihood of generating erroneous kinetochore-microtubule attachments. Most of these attachments are sensed by the Spindle Assembly Checkpoint (SAC), which generates a "wait-anaphase" signal until all chromosomes are correctly attached (Lara-Gonzalez et al., 2012). However, merotelic attachments, which occur when one kinetochore is bound to microtubules emanating from different poles, are usually invisible to the SAC (Gregan et al., 2011). Consequently, cells with incompletely separated centrosomes at NEB tend to have a higher rate of chromosome missegregation (Kaseda et al., 2012; Silkworth et al., 2012; Nunes et al., 2020).

During metaphase, cortical force generators dictate spindle orientation (Thery et al., 2007; Kotak et al., 2012) by sensing external cues (Thery et al., 2005; Toyoshima and Nishida, 2007; Fink et al., 2011). However, during the initial stages of mitosis, as cells round up and the actomyosin cortex is yet to be assembled, these cortical force generators are not present (Kiyomitsu and Cheeseman, 2012; Kotak et al., 2012). Therefore, it is likely that the cues required for centrosome positioning during early mitosis are not provided by external signals, but rather derive from an internal input. One such signal could be provided by the NE-specific pool of dynein, that is dependent on association with the RanBP2-BicD2 (Splinter et al., 2010) or Nup133/CENPF/NudE-NudEL (Bolhy et al., 2011) pathways, in a CDK1dependent manner (Baffet et al., 2015). Accordingly, preventing dynein loading on the NE results in a failure to separate (van Heesbeen et al., 2013; De Simone et al., 2016; Boudreau et al., 2019) and correctly position centrosomes (Splinter et al., 2010; Bolhy et al., 2011; Nunes et al., 2020). The manner in which the properties of the prophase nucleus dictate dynein localization and activity to ensure positioning of centrosomes on the shortest nuclear axis and avert chromosome missegregation remains an open question.

\section{THE NUCLEUS AND NUCLEO-CYTOSKELETAL COUPLING}

The cell nucleus is encased by a NE that acts as a barrier between cytoplasmic and nuclear components. The NE is composed of and inner (INM) and an outer (ONM) nuclear membrane, NPCs and a dense NL. The NL consists mainly of A-type and B-type Lamins, which are type $\mathrm{V}$ intermediate filaments that provide structural support to the nucleus (Dechat et al., 2010). Lamins can interact with chromatin and with NE membrane proteins, such as Emerin, LAP2, or nuclear soluble factors such as barrier-toautointegration factor (BAF) (Ungricht and Kutay, 2017).

The nucleus is continuously under the influence of external forces. When physical forces are applied to the cell, they are decoded into biochemical signals in a process known as mechanotransduction. This process starts at the cell membrane, where adhesion complexes sense external cues (Sun et al., 2016). The cytoskeleton then relays these signals to the nucleus through the linker of nucleoskeleton and cytoskeleton (LINC) complex (Lombardi and Lammerding, 2011), which triggers a nuclear mechanical response that depends on the NL (Stephens et al., 2017), chromatin condensation (Schreiner et al., 2015; Stephens et al., 2017) and nucleo-cytoskeletal coupling (Lombardi and Lammerding, 2011). This ultimately leads to changes in nuclear structure and organization (Lammerding, 2011; Maurer and Lammerding, 2019) and regulates cell cycle progression (Uroz et al., 2018; Vitiello et al., 2019).

As mentioned above, a series of well-coordinated events ensure timely mitotic entry, starting with chromosome condensation (Antonin and Neumann, 2016) and cytoskeletal reorganization (Ramkumar and Baum, 2016; Champion et al., 2017), and culminating in nuclear permeabilization (Beaudouin et al., 2002; Salina et al., 2002). In higher eukaryotes, nuclear permeabilization starts with the removal of nucleoporins from NPCs (Dultz et al., 2008; Katsani et al., 2008), which triggers a loss of the nucleo-cytoplasmic boundary. The process continues with the contribution of dynein-driven, microtubule-dependent pulling forces, which generate holes in the nucleus and assist in membrane clearing from chromosomes (Beaudouin et al., 2002; Salina et al., 2002; Muhlhausser and Kutay, 2007). Finally, the NL depolymerizes, due to Lamin phosphorylation and consequent nucleoplasmic release (Heald and McKeon, 1990; Peter et al., 1990; Georgatos et al., 1997). These steps are essential to allow the interaction of microtubules with kinetochores on mitotic chromosomes. In interphase, the mechanical response of the nucleus is dictated by the chromatin condensation state (Stephens et al., 2017), the levels of Lamin A (Buxboim et al., 2017) and the interaction of heterochromatin with the nuclear membrane (Schreiner et al., 2015). Remarkably, as cells transition from G2 to mitosis, all the above components are extensively modified. Phosphorylation of Lamin A by 
CDK1 (Heald and McKeon, 1990; Peter et al., 1990), triggers its disassembly from the $\mathrm{NL}$ and consequent release into the nucleoplasm (Georgatos et al., 1997). Although direct measurements of nuclear stiffness at this stage have not been made, it is possible to assume that NL depolymerization significantly changes the mechanical response of the nucleus, facilitating NEB. Accordingly, MEFs with Lamin A/C deficiency show impaired nuclear stiffness and mechanics (Lammerding et al., 2004, 2006). This is in line with observations in human cells, showing that loss of Lamin A renders nuclei softer (Pajerowski et al., 2007) and prone to rupture (Earle et al., 2020). Taken together, these observations implicate the NL in the mechanical stability of the nucleus and highlight the need for its depolymerization during prophase (Georgatos et al., 1997), to facilitate microtubule-dependent nuclear permeabilization (Beaudouin et al., 2002; Salina et al., 2002). At the same time, mitotic chromosomes condense, altering their structure and stiffness (Stephens et al., 2017; Sun et al., 2018; Biggs et al., 2019). Evidence from metaphase chromosomes isolated from HeLa cells showed this process to be largely dependent on condensins (Sun et al., 2018), although histone post-translational modifications also play an important role (Biggs et al., 2019). Finally, the actin cytoskeleton, which is connected to the nucleus through the LINC complex (Versaevel et al., 2014), is remodeled to assemble a mitotic cortex (Ramkumar and Baum, 2016). This remodeling might modify the connections between the cytoskeleton and the nucleus, contributing to changes in nuclear mechanics. Accordingly, disrupting the actin cytoskeleton in NIH3T3 cells was sufficient to modify the compressive forces exerted on the nucleus and induce changes in chromatin organization ( $\mathrm{Li}$ et al., 2014). Taken together, these studies suggest that the mechanical properties of the nucleus change during the G2-M transition and warrant further investigation on the functional relevance of nuclear mechanics for mitotic fidelity.

While measurements of the mechanical properties of the nucleus during the G2-M transition are still missing, there is already significant evidence to support a role for the nucleus and nucleus-associated components in other steps of mitosis, namely in determining chromosome segregation fidelity. One key component in nuclear mechanotransduction is the aforementioned LINC complex (Figure 2). This complex consists of SUN (Sad1, UNC84) proteins in the INM and KASH

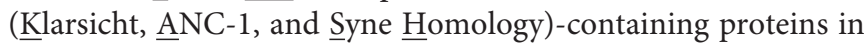
the ONM (Starr and Fridolfsson, 2010). Importantly, studies in MEFs using a microneedle assay to apply controlled cytoskeletal strains, in combination with dominant-negative forms of SUN and KASH proteins, showed that an intact LINC complex is essential for force transmission to the nucleus (Lombardi et al., 2011). Similarly, in cultured human cells, depletion of both SUN1 and SUN2 delayed NE disassembly (Figure 2), similarly to what is observed after microtubule depolymerization with nocodazole (Turgay et al., 2014). Consequently, centrosome separation is disrupted (Stiff et al., 2020) and mitotic progression affected (Turgay et al., 2014). Moreover, an intact LINC complex is essential during early mitosis for decreasing chromosome scattering (Booth et al., 2019), likely facilitating their capture and congression (Booth et al., 2019; Stiff et al., 2020). Importantly, the LINC complex also directly associates with dynein on the NE to control nuclear migration (Malone et al., 2003; Zhang et al., 2009; Fridolfsson and Starr, 2010; Yu et al., 2011) and meiotic chromosome movement (Chikashige et al., 2006; Sato et al., 2009). Given that an intact LINC complex is required for force transmission to the nucleus (Lombardi et al., 2011) and NE dynein is essential for centrosome positioning (Nunes et al., 2020), it is possible that LINC-mediated mechanical forces could play an important part in determining correct centrosome positioning by ensuring timely dynein loading. Accordingly, depletion of SUN1 and SUN2 is sufficient to abolish NE dynein localization (Turgay et al., 2014; Nunes et al., 2019). Whether this is directly due to a defect in nuclear mechanotransduction triggered by loss of the LINC complex remains unknown (Figure 2).

Other nuclear components have also been implicated in spindle assembly and chromosome segregation. Blocking the removal of NE membranes at mitotic onset leads to defects in spindle assembly and chromosome segregation (Turgay et al., 2014; Champion et al., 2019). Similar defects in membranes removal could also be triggered by expression of a mutant version of Lamin A that is observed in progeria patients (Dechat et al., 2007). However, Lamin A, together with BAF and LAP $2 \alpha$, is also directly involved in spindle assembly and orientation by targeting dynein to the cell cortex (Qi et al., 2015). Moreover, chromosome distribution is altered in LMNA mutant fibroblasts (Meaburn et al., 2007). Such alterations could directly affect chromosome distribution during early mitosis, disrupting the disk-like prometaphase chromosome organization, essential for spindle assembly (Magidson et al., 2011). Taken together, these defects could explain why Lamin A/C deficiency leads to aneuploidy and chromosomal instability (Dechat et al., 2007; Capo-chichi et al., 2011; Capo-Chichi et al., 2016; Smith et al., 2018). Interestingly, mitotic problems are not exclusive to Lamin A. In C. elegans, it was shown that reduced levels of MAN1 and Emerin, INM proteins which interact with Lamins and the LINC complex (Piccus and Brayson, 2020), trigger "anaphase-bridged chromatin" (Liu et al., 2003), a phenotype also observed in a mouse model of laminopathy (Pratt et al., 2011), and in human cells with reduced Lamin A levels (Cao et al., 2007). Moreover, loss of Lamin B2 in human cells was also shown to trigger chromosomal instability, by interfering with the spatial organization of chromosomes (Ranade et al., 2017) and affecting spindle assembly (Kuga et al., 2014).

Although these reports are compelling, there are alternative hypotheses to explain how alterations in Lamins could indirectly trigger mitotic defects. Chromatin is thought to associate with the NL through specific sequences known as laminaassociated domains (LADs) (van Steensel and Belmont, 2017) that are considered to be transcriptionally repressive regions (Guelen et al., 2008) and help organize chromosomes within the nuclear volume (Mewborn et al., 2010). Notably, Lamin A phosphorylation on Ser22, essential for NL depolymerization during mitotic entry (Heald and McKeon, 1990), was recently shown to act as a transcriptional regulator (Ikegami et al., 2020), 


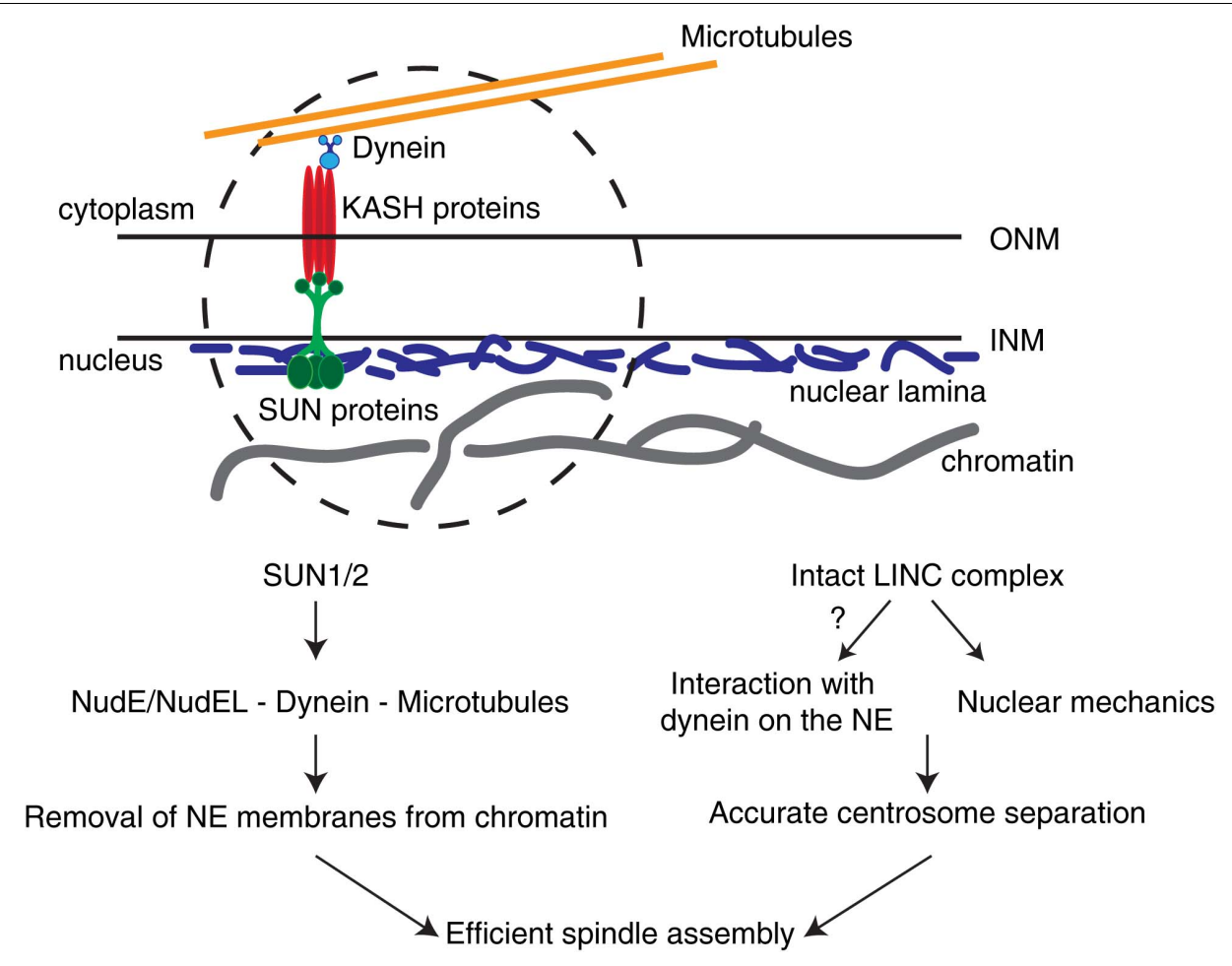

FIGURE 2 | The LINC complex in early spindle assembly and chromosome segregation. The LINC complex consists of SUN1/2 trimers on the inner nuclear membrane (INM) and KASH proteins on the outer nuclear membrane (ONM). In somatic cells, different KASH proteins differentially bind to specific motors (e.g., dynein) or to distinct cytoskeletal components. These complexes are able to sense forces relayed by the cytoskeleton and transmit them to the nuclear interior. During the G2-M transition, SUN proteins are required to remove NE membranes from chromatin and position centrosomes. In addition, an intact LINC complex is necessary for correct centrosome separation. Whether this is due to LINC complex-dependent loading of dynein on the NE or to nuclear mechanotransduction remains unclear.

which could explain why LMNA mutants show altered gene expression patterns (Mewborn et al., 2010). Whether the mitotic defects triggered by Lamin A loss could be due to changes in its transcriptional program remains to be determined.

\section{MECHANICAL FORCES IN CELL CYCLE PROGRESSION}

The link between mechanical forces and the cell cycle has long been recognized (Chen et al., 1997; Huang et al., 1998). In capillary endothelial cells, tractional forces are sufficient to trigger the G1-S transition by increasing Cyclin D1 levels and downregulating the cell cycle inhibitor p $27^{\mathrm{Kip}}$ (Huang et al., 1998). This likely occurs by force-mediated nuclear deformation that triggers the activation of transcription factors such as TEAD and AP1, leading to the induction of genes that promote the G1-S transition (Aureille et al., 2019). In agreement with these observations, recent data obtained in MDCK monolayers showed that both tension and mechanical energy are good predictors of G1 duration (Uroz et al., 2018).

Other stages of the cell cycle are also mechanically regulated. In fact, the organization pattern of actomyosin forces sets the duration of the S and G2 phases, by modulating centriole duplication and Plk4 recruitment (Vitiello et al., 2019). In addition, there is evidence from MDCK monolayers and isolated cells, for a decrease in cell traction forces during G2 and early mitosis (Uroz et al., 2018; Vianay et al., 2018; Nunes et al., 2020), which occurs in tandem with the disassembly of FAs (Dao et al., 2009) and an increased expression of DEPDC1B (Marchesi et al., 2014). How these events are coordinated is still unclear. It is possible that, during the G2-M transition, a FA-generated mechanical signal is relayed from the cell membrane to the nucleus, triggering DEPDC1B expression, which would then act as a RhoA inhibitor to regulate adhesion dynamics (Marchesi et al., 2014). This, together with increased CDK1 activity (Jones et al., 2018), would set the timing for FA disassembly and mitotic entry (Gavet and Pines, 2010a,b; Marchesi et al., 2014).

\section{CONCLUSION}

Efficient assembly of a mitotic spindle requires accurate coordination between cytoplasmic and nuclear events. This is achieved, at least partly, by the activity and localization of the Cyclin B1-CDK1 complex (Gavet and Pines, 2010a,b). In the cytoplasm, CDK1 enables centrosome separation (Smith et al., 2011) and induces global changes in microtubule dynamics by directly phosphorylating microtubule-associated 
proteins (MAPs) and modifying their microtubule binding capacity (Lamb et al., 1990; Verde et al., 1990; Verde et al., 1992). On the other hand, inside the nucleus, CDK1 contributes to NPC disassembly (Linder et al., 2017) and NL depolymerization (Heald and McKeon, 1990; Peter et al., 1990). These biochemical events trigger a global cellular reorganization that allows the assembly of an actomyosin cortex and a microtubule-based mitotic spindle.

In addition to the biochemical pathways controlling mitotic entry, it has long been proposed that mechanical forces also regulate the cell cycle (Huang et al., 1998; Lancaster et al., 2013; Uroz et al., 2018; Vianay et al., 2018; Aureille et al., 2019). High cellular tension triggers a transition from G1 to S phase (Huang et al., 1998; Uroz et al., 2018; Aureille et al., 2019) and also regulates the length of the S-G2 phases of the cell cycle (Vitiello et al., 2019). In part, this could be due to tension-generated NE deformation that is sufficient to trigger mechanically-activated transcriptional programs (Aureille et al., 2019) and affect cell proliferation (Versaevel et al., 2012). As cells progress toward mitosis, tension decreases (Uroz et al., 2018; Vianay et al., 2018; Nunes et al., 2020), likely reflecting adhesion complex disassembly (Dao et al., 2009), mediated by increased levels of Cyclin B1 (Gavet and Pines, 2010b; Jones et al., 2018). Overall, these observations highlight the interactions between physical forces and the cell cycle machinery and raise the interesting possibility that mechanical forces could directly influence the biochemical signals that control mitotic entry, contributing to the fidelity of chromosome segregation. As new tools emerge that allow us to probe the physical properties of cells, we will gain further insight on how the spatiotemporal dynamics of nuclear mechanics and

\section{REFERENCES}

Abe, S., Nagasaka, K., Hirayama, Y., Kozuka-Hata, H., Oyama, M., Aoyagi, Y., et al. (2011). The initial phase of chromosome condensation requires Cdk1mediated phosphorylation of the CAP-D3 subunit of condensin II. Genes Dev. 25, 863-874. doi: 10.1101/gad.2016411

Antonin, W., and Neumann, H. (2016). Chromosome condensation and decondensation during mitosis. Curr. Opin. Cell Biol. 40, 15-22. doi: 10.1016/j. ceb.2016.01.013

Aureille, J., Buffière-Ribot, V., Harvey, B. E., Boyault, C., Pernet, L., Andersen, T., et al. (2019). Nuclear envelope deformation controls cell cycle progression in response to mechanical force. EMBO Rep. 20, e48084.

Baffet, A. D., Hu, D. J., and Vallee, R. B. (2015). Cdk1 activates pre-mitotic nuclear envelope dynein recruitment and apical nuclear migration in neural stem cells. Dev. Cell 33, 703-716. doi: 10.1016/j.devcel.2015.04.022

Beaudouin, J., Gerlich, D., Daigle, N., Eils, R., and Ellenberg, J. (2002). Nuclear envelope breakdown proceeds by microtubule-induced tearing of the lamina. Cell 108, 83-96. doi: 10.1016/s0092-8674(01)00627-4

Biggs, R., Liu, P. Z., Stephens, A. D., and Marko, J. F. (2019). Effects of altering histone posttranslational modifications on mitotic chromosome structure and mechanics. Mol. Biol. Cell 30, 820-827. doi: 10.1091/mbc.e18-090592

Bishop, J. D., Han, Z., and Schumacher, J. M. (2005). The Caenorhabditis elegans Aurora B kinase AIR-2 phosphorylates and is required for the localization of a BimC kinesin to meiotic and mitotic spindles. Mol. Biol. Cell 16, 742-756. doi: 10.1091/mbc.e04-08-0682

Blangy, A., Lane, H. A., D’herin, P., Harper, M., Kress, M., and Nigg, E. A. (1995). Phosphorylation by $\mathrm{p} 34 \mathrm{cdc} 2$ regulates spindle association of human Eg5, a nucleus-cytoskeleton coupling contribute to spindle assembly efficiency and chromosome segregation fidelity.

\section{AUTHOR CONTRIBUTIONS}

MD, JL, and JF jointly wrote the manuscript. JF provided the conceptual framework. All authors contributed to the article and approved the submission.

\section{FUNDING}

Work in the Biophysics of Cell Division Laboratory was supported by Portuguese funds through FCT-Fundação para a Ciência e a Tecnologia/Ministério da Ciência, Tecnologia e Ensino Superior in the framework of the project PTDC/BIA-CEL/6740/2020. MD was supported by the grant $\mathrm{PD} / \mathrm{BD} / 135548 / 2018$ from the BiotechHealth FCTfunded Ph.D. program. JL was supported by the grant SFRH/BD/147169/2019 from FCT.

\section{ACKNOWLEDGMENTS}

We would like to thank all the members of the Biophysics of Cell Division Laboratory for their critical reading of the manuscript. We would like to apologize to all colleagues whose work contributed for our current knowledge on the mechanisms of mitotic entry, but which could not be cited due to space limitations.

kinesin-related motor essential for bipolar spindle formation in vivo. Cell 83, 1159-1169. doi: 10.1016/0092-8674(95)90142-6

Bolhy, S., Bouhlel, I., Dultz, E., Nayak, T., Zuccolo, M., Gatti, X., et al. (2011). A Nup133-dependent NPC-anchored network tethers centrosomes to the nuclear envelope in prophase. J. Cell Biol. 192, 855-871. doi: 10.1083/jcb.20100 7118

Booth, A. J. R., Yue, Z., Eykelenboom, J. K., Stiff, T., Luxton, G. W. G., Hochegger, H., et al. (2019). Contractile acto-myosin network on nuclear envelope remnants positions human chromosomes for mitosis. Elife 8:e46902.

Boudreau, V., Chen, R., Edwards, A., Sulaimain, M., and Maddox, P. S. (2019). PP2A-B55/SUR-6 collaborates with the nuclear lamina for centrosome separation during mitotic entry. Mol. Biol. Cell 30, 876-886.

Bovellan, M., Romeo, Y., Biro, M., Boden, A., Chugh, P., Yonis, A., et al. (2014). Cellular control of cortical actin nucleation. Curr. Biol. 24, 1628-1635. doi: 10.1016/j.cub.2014.05.069

Buxboim, A., Irianto, J., Swift, J., Athirasala, A., Shin, J. W., Rehfeldt, F., et al. (2017). Coordinated increase of nuclear tension and lamin-A with matrix stiffness outcompetes lamin-B receptor that favors soft tissue phenotypes. Mol. Biol. Cell 28, 3333-3348. doi: 10.1091/mbc.e17-06-0393

Cao, K., Capell, B. C., Erdos, M. R., Djabali, K., and Collins, F. S. (2007). A lamin A protein isoform overexpressed in Hutchinson-Gilford progeria syndrome interferes with mitosis in progeria and normal cells. Proc. Natl. Acad. Sci. U.S.A. 104, 4949-4954. doi: 10.1073/pnas.0611640104

Capo-chichi, C. D., Cai, K. Q., Simpkins, F., Ganjei-Azar, P., Godwin, A. K., and Xu, X. X. (2011). Nuclear envelope structural defects cause chromosomal numerical instability and aneuploidy in ovarian cancer. BMC Med. 9:28. doi: 10.1186/1741-7015-9-28 
Capo-Chichi, C. D., Yeasky, T. M., Smith, E. R., and Xu, X. X. (2016). Nuclear envelope structural defect underlies the main cause of aneuploidy in ovarian carcinogenesis. BMC Cell Biol. 17:37. doi: 10.1186/s12860-016-0114-8

Cattin, C. J., Duggelin, M., Martinez-Martin, D., Gerber, C., Muller, D. J., and Stewart, M. P. (2015). Mechanical control of mitotic progression in single animal cells. Proc. Natl. Acad. Sci. U.S.A. 112, 11258-11263. doi: 10.1073/pnas. 1502029112

Champion, L., Linder, M. I., and Kutay, U. (2017). Cellular reorganization during mitotic entry. Trends Cell Biol. 27, 26-41. doi: 10.1016/j.tcb.2016.07.004

Champion, L., Pawar, S., Luithle, N., Ungricht, R., and Kutay, U. (2019). Dissociation of membrane-chromatin contacts is required for proper chromosome segregation in mitosis. Mol. Biol. Cell 30, 427-440. doi: 10.1091/ mbc.e18-10-0609

Chen, C. S., Mrksich, M., Huang, S., Whitesides, G. M., and Ingber, D. E. (1997). Geometric control of cell life and death. Science 276, 1425-1428. doi: 10.1126/ science.276.5317.1425

Chikashige, Y., Tsutsumi, C., Yamane, M., Okamasa, K., Haraguchi, T., and Hiraoka, Y. (2006). Meiotic proteins bqt1 and bqt2 tether telomeres to form the bouquet arrangement of chromosomes. Cell 125, 59-69.

Chugh, P., and Paluch, E. K. (2018). The actin cortex at a glance. J. Cell Sci. 131:jcs186254. doi: $10.1242 /$ jcs. 186254

Dao, V. T., Dupuy, A. G., Gavet, O., Caron, E., and De Gunzburg, J. (2009). Dynamic changes in Rapl activity are required for cell retraction and spreading during mitosis. J. Cell Sci. 122, 2996-3004. doi: 10.1242/jcs.041301

De Simone, A., Nedelec, F., and Gonczy, P. (2016). Dynein transmits polarized actomyosin cortical flows to promote centrosome separation. Cell Rep. 14, 2250-2262. doi: 10.1016/j.celrep.2016.01.077

Dechat, T., Adam, S. A., Taimen, P., Shimi, T., and Goldman, R. D. (2010). Nuclear lamins. Cold Spring Harb. Perspect. Biol. 2:a000547.

Dechat, T., Shimi, T., Adam, S. A., Rusinol, A. E., Andres, D. A., Spielmann, H. P., et al. (2007). Alterations in mitosis and cell cycle progression caused by a mutant lamin A known to accelerate human aging. Proc. Natl. Acad. Sci. U.S.A. 104, 4955-4960. doi: 10.1073/pnas.0700854104

Dultz, E., Zanin, E., Wurzenberger, C., Braun, M., Rabut, G., Sironi, L., et al. (2008). Systematic kinetic analysis of mitotic dis- and reassembly of the nuclear pore in living cells. J. Cell Biol. 180, 857-865. doi: 10.1083/jcb.200707026

Earle, A. J., Kirby, T. J., Fedorchak, G. R., Isermann, P., Patel, J., Iruvanti, S., et al. (2020). Mutant lamins cause nuclear envelope rupture and DNA damage in skeletal muscle cells. Nat. Mater. 19, 464-473.

Fink, J., Carpi, N., Betz, T., Betard, A., Chebah, M., Azioune, A., et al. (2011). External forces control mitotic spindle positioning. Nat. Cell Biol. 13, 771-778. doi: $10.1038 /$ ncb2269

Fischer-Friedrich, E., Toyoda, Y., Cattin, C. J., Müller, D. J., Hyman, A. A., and Jülicher, F. (2016). Rheology of the active cell cortex in mitosis. Biophys. J. 111, 589-600. doi: 10.1016/j.bpj.2016.06.008

Fridolfsson, H. N., and Starr, D. A. (2010). Kinesin-1 and dynein at the nuclear envelope mediate the bidirectional migrations of nuclei. J. Cell Biol. 191, 115-128. doi: $10.1083 /$ jcb.201004118

Gavet, O., and Pines, J. (2010a). Activation of cyclin B1-Cdk1 synchronizes events in the nucleus and the cytoplasm at mitosis. J. Cell Biol. 189, 247-259. doi: 10.1083/jcb.200909144

Gavet, O., and Pines, J. (2010b). Progressive activation of CyclinB1-Cdk1 coordinates entry to mitosis. Dev. Cell 18, 533-543. doi: 10.1016/j.devcel.2010. 02.013

Georgatos, S. D., Pyrpasopoulou, A., and Theodoropoulos, P. A. (1997). Nuclear envelope breakdown in mammalian cells involves stepwise lamina disassembly and microtubule-drive deformation of the nuclear membrane. J. Cell Sci. 110(Pt 17), 2129-2140.

Gheghiani, L., Loew, D., Lombard, B., Mansfeld, J., and Gavet, O. (2017). PLK1 activation in Late G2 Sets up commitment to mitosis. Cell Rep. 19, 2060-2073. doi: 10.1016/j.celrep.2017.05.031

Gibson, M. C., Patel, A. B., Nagpal, R., and Perrimon, N. (2006). The emergence of geometric order in proliferating metazoan epithelia. Nature 442, 1038-1041. doi: 10.1038/nature05014

Gregan, J., Polakova, S., Zhang, L., Tolic-Norrelykke, I. M., and Cimini, D. (2011). Merotelic kinetochore attachment: causes and effects. Trends Cell Biol. 21, 374-381. doi: 10.1016/j.tcb.2011.01.003
Guelen, L., Pagie, L., Brasset, E., Meuleman, W., Faza, M. B., Talhout, W., et al. (2008). Domain organization of human chromosomes revealed by mapping of nuclear lamina interactions. Nature 453, 948-951. doi: 10.1038/nature 06947

Hayden, J. H., Bowser, S. S., and Rieder, C. L. (1990). Kinetochores capture astral microtubules during chromosome attachment to the mitotic spindle: direct visualization in live newt lung cells. J. Cell Biol. 111, 1039-1045. doi: 10.1083/ jcb.111.3.1039

Heald, R., and Khodjakov, A. (2015). Thirty years of search and capture: the complex simplicity of mitotic spindle assembly. J. Cell Biol. 211, 1103-1111. doi: $10.1083 /$ jcb. 201510015

Heald, R., and McKeon, F. (1990). Mutations of phosphorylation sites in lamin A that prevent nuclear lamina disassembly in mitosis. Cell 61, 579-589. doi: 10.1016/0092-8674(90)90470-y

Heck, M. M., Pereira, A., Pesavento, P., Yannoni, Y., Spradling, A. C., and Goldstein, L. S. (1993). The kinesin-like protein KLP61F is essential for mitosis in Drosophila. J. Cell Biol. 123, 665-679. doi: 10.1083/jcb.123.3.665

Huang, S., Chen, C. S., and Ingber, D. E. (1998). Control of cyclin D1, p27(Kip1), and cell cycle progression in human capillary endothelial cells by cell shape and cytoskeletal tension. Mol. Biol. Cell 9, 3179-3193. doi: 10.1091/mbc.9.11.3179

Ikegami, K., Secchia, S., Almakki, O., Lieb, J. D., and Moskowitz, I. P. (2020). Phosphorylated Lamin A/C in the nuclear interior binds active enhancers associated with abnormal transcription in progeria. Dev. Cell 52, 699-713.e11.

Jones, M. C., Askari, J. A., Humphries, J. D., and Humphries, M. J. (2018). Cell adhesion is regulated by CDK1 during the cell cycle. J. Cell Biol. 217, 3203-3218. doi: $10.1083 /$ jcb. 201802088

Kaseda, K., Mcainsh, A. D., and Cross, R. A. (2012). Dual pathway spindle assembly increases both the speed and the fidelity of mitosis. Biol. Open 1, 12-18. doi: 10.1242/bio.2011012

Kashina, A. S., Scholey, J. M., Leszyk, J. D., and Saxton, W. M. (1996). An essential bipolar mitotic motor. Nature 384:225. doi: 10.1038/384225a0

Katsani, K. R., Karess, R. E., Dostatni, N., and Doye, V. (2008). In vivo dynamics of Drosophila nuclear envelope components. Mol. Biol. Cell 19, 3652-3666. doi: 10.1091/mbc.e07-11-1162

Kiyomitsu, T., and Cheeseman, I. M. (2012). Chromosome- and spindle-polederived signals generate an intrinsic code for spindle position and orientation. Nat. Cell Biol. 14, 311-317. doi: 10.1038/ncb2440

Kotak, S., Busso, C., and Gonczy, P. (2012). Cortical dynein is critical for proper spindle positioning in human cells. J. Cell Biol. 199, 97-110. doi: 10.1083/jcb. 201203166

Kuga, T., Nie, H., Kazami, T., Satoh, M., Matsushita, K., Nomura, F., et al. (2014). Lamin B2 prevents chromosome instability by ensuring proper mitotic chromosome segregation. Oncogenesis 3:e94. doi: 10.1038/oncsis.2014.6

Kunda, P., Pelling, A. E., Liu, T., and Baum, B. (2008). Moesin controls cortical rigidity, cell rounding, and spindle morphogenesis during mitosis. Curr. Biol. 18, 91-101. doi: 10.1016/j.cub.2007.12.051

Lamb, N. J., Fernandez, A., Watrin, A., Labbe, J. C., and Cavadore, J. C. (1990). Microinjection of p34cdc2 kinase induces marked changes in cell shape, cytoskeletal organization, and chromatin structure in mammalian fibroblasts. Cell 60, 151-165. doi: 10.1016/0092-8674(90)90725-t

Lammerding, J. (2011). Mechanics of the nucleus. Compr. Physiol. 1, 783-807.

Lammerding, J., Fong, L. G., Ji, J. Y., Reue, K., Stewart, C. L., Young, S. G., et al. (2006). Lamins A and C but not lamin B1 regulate nuclear mechanics. J. Biol. Chem. 281, 25768-25780. doi: 10.1074/jbc.m513511200

Lammerding, J., Schulze, P. C., Takahashi, T., Kozlov, S., Sullivan, T., Kamm, R. D., et al. (2004). Lamin A/C deficiency causes defective nuclear mechanics and mechanotransduction. J. Clin. Invest. 113, 370-378. doi: 10.1172/jci200419670

Lancaster, O. M., Le Berre, M., Dimitracopoulos, A., Bonazzi, D., ZlotekZlotkiewicz, E., Picone, R., et al. (2013). Mitotic rounding alters cell geometry to ensure efficient bipolar spindle formation. Dev. Cell 25, 270-283. doi: 10.1016/ j.devcel.2013.03.014

Lara-Gonzalez, P., Westhorpe, F. G., and Taylor, S. S. (2012). The spindle assembly checkpoint. Curr. Biol. 22, R966-R980.

Li, Q., Kumar, A., Makhija, E., and Shivashankar, G. V. (2014). The regulation of dynamic mechanical coupling between actin cytoskeleton and nucleus by matrix geometry. Biomaterials 35, 961-969. doi: 10.1016/j.biomaterials.2013. 10.037 
Linder, M. I., Kohler, M., Boersema, P., Weberruss, M., Wandke, C., Marino, J., et al. (2017). Mitotic Disassembly of nuclear pore complexes involves CDK1and PLK1-mediated phosphorylation of key interconnecting nucleoporins. Dev. Cell 43, 141-156.e7.

Liu, J., Lee, K. K., Segura-Totten, M., Neufeld, E., Wilson, K. L., and Gruenbaum, Y. (2003). MAN1 and emerin have overlapping function(s) essential for chromosome segregation and cell division in Caenorhabditis elegans. Proc. Natl. Acad. Sci. U.S.A. 100, 4598-4603. doi: 10.1073/pnas.0730821100

Lombardi, M. L., Jaalouk, D. E., Shanahan, C. M., Burke, B., Roux, K. J., and Lammerding, J. (2011). The interaction between nesprins and sun proteins at the nuclear envelope is critical for force transmission between the nucleus and cytoskeleton. J. Biol. Chem. 286, 26743-26753. doi: 10.1074/jbc.m111.233700

Lombardi, M. L., and Lammerding, J. (2011). Keeping the LINC: the importance of nucleocytoskeletal coupling in intracellular force transmission and cellular function. Biochem. Soc. Trans. 39, 1729-1734. doi: 10.1042/bst20110686

Maddox, A. S., and Burridge, K. (2003). RhoA is required for cortical retraction and rigidity during mitotic cell rounding. J. Cell Biol. 160, 255-265. doi: 10. $1083 /$ jcb. 200207130

Magidson, V., O'connell, C. B., Loncarek, J., Paul, R., Mogilner, A., and Khodjakov, A. (2011). The spatial arrangement of chromosomes during prometaphase facilitates spindle assembly. Cell 146, 555-567. doi: 10.1016/j.cell.2011.07.012

Malone, C. J., Misner, L., Le Bot, N., Tsai, M. C., Campbell, J. M., Ahringer, J., et al. (2003). The C. elegans hook protein, ZYG-12, mediates the essential attachment between the centrosome and nucleus. Cell 115, 825-836. doi: 10.1016/s00928674(03)00985- 1

Marchesi, S., Montani, F., Deflorian, G., D’antuono, R., Cuomo, A., Bologna, S., et al. (2014). DEPDC1B coordinates de-adhesion events and cell-cycle progression at mitosis. Dev. Cell 31, 420-433. doi: 10.1016/j.devcel.2014.09.009

Matthews, H. K., Delabre, U., Rohn, J. L., Guck, J., Kunda, P., and Baum, B. (2012). Changes in Ect2 localization couple actomyosin-dependent cell shape changes to mitotic progression. Dev. Cell 23, 371-383. doi: 10.1016/j.devcel.2012.06.003

Matthews, H. K., Ganguli, S., Plak, K., Taubenberger, A. V., Win, Z., Williamson, M., et al. (2020). Oncogenic signaling alters cell shape and mechanics to facilitate cell division under confinement. Dev. Cell 52, 563-573.e3.

Maurer, M., and Lammerding, J. (2019). The driving force: nuclear mechanotransduction in cellular function, fate, and disease. Annu. Rev. Biomed. Eng. 21, 443-468. doi: 10.1146/annurev-bioeng-060418-052139

Mchedlishvili, N., Matthews, H. K., Corrigan, A., and Baum, B. (2018). Two-step interphase microtubule disassembly aids spindle morphogenesis. BMC Biol. 16:14. doi: 10.1186/s12915-017-0478-z

Meaburn, K. J., Cabuy, E., Bonne, G., Levy, N., Morris, G. E., Novelli, G., et al. (2007). Primary laminopathy fibroblasts display altered genome organization and apoptosis. Aging Cell 6, 139-153. doi: 10.1111/j.1474-9726.2007.00270.x

Mewborn, S. K., Puckelwartz, M. J., Abuisneineh, F., Fahrenbach, J. P., Zhang, Y., Macleod, H., et al. (2010). Altered chromosomal positioning, compaction, and gene expression with a lamin A/C gene mutation. PLoS One 5:e14342. doi: 10.1371 /journal.pone.0014342

Mitchison, T. J. (1992). Actin based motility on retraction fibers in mitotic PtK2 cells. Cell Motil. Cytoskeleton 22, 135-151. doi: 10.1002/cm.970220207

Muhlhausser, P., and Kutay, U. (2007). An in vitro nuclear disassembly system reveals a role for the RanGTPase system and microtubule-dependent steps in nuclear envelope breakdown. J. Cell Biol. 178, 595-610. doi: 10.1083/jcb. 200703002

Nam, H. J., Naylor, R. M., and Van Deursen, J. M. (2015). Centrosome dynamics as a source of chromosomal instability. Trends Cell Biol. 25, 65-73. doi: 10.1016/j. tcb.2014.10.002

Nunes, V., Dantas, M., Vitiello, E., Wang, E., Carpi, N., Balland, M., et al. (2019). Mechanosensitive nuclear asymmetries define a bipolar spindle scaffold to ensure mitotic fidelity. bioRxiv. [Preprint]. doi: 10.1101/526939

Nunes, V., Dantas, M., Vitiello, E., Wang, I., Carpi, N., Balland, M., et al. (2020). Centrosome-nuclear axis repositioning drives the assembly of a bipolar spindle scaffold to ensure mitotic fidelity. Mol. Biol. Cell 31, 1675-1690. doi: 10.1091/ mbc.e20-01-0047

Pajerowski, J. D., Dahl, K. N., Zhong, F. L., Sammak, P. J., and Discher, D. E. (2007). Physical plasticity of the nucleus in stem cell differentiation. Proc. Natl. Acad. Sci. U.S.A. 104, 15619-15624. doi: 10.1073/pnas.0702576104
Peter, M., Nakagawa, J., Doree, M., Labbe, J. C., and Nigg, E. A. (1990). In vitro disassembly of the nuclear lamina and $\mathrm{M}$ phase-specific phosphorylation of lamins by cdc2 kinase. Cell 61, 591-602. doi: 10.1016/0092-8674(90)90471-p

Piccus, R., and Brayson, D. (2020). The nuclear envelope: LINCing tissue mechanics to genome regulation in cardiac and skeletal muscle. Biol. Lett. 16:20200302. doi: 10.1098/rsbl.2020.0302

Pratt, C. H., Curtain, M., Donahue, L. R., and Shopland, L. S. (2011). Mitotic defects lead to pervasive aneuploidy and accompany loss of RB1 activity in mouse LmnaDhe dermal fibroblasts. PLoS One 6:e18065. doi: 10.1371/journal.pone. 0018065

Qi, R., Xu, N., Wang, G., Ren, H., Li, S., Lei, J., et al. (2015). The laminA/C-LAP2alpha-BAF1 protein complex regulates mitotic spindle assembly and positioning. J. Cell Sci. 128, 2830-2841. doi: 10.1242/jcs.164566

Ramanathan, S. P., Helenius, J., Stewart, M. P., Cattin, C. J., Hyman, A. A., and Muller, D. J. (2015). Cdk1-dependent mitotic enrichment of cortical myosin II promotes cell rounding against confinement. Nat. Cell Biol. 17, 148-159. doi: $10.1038 /$ ncb3098

Ramkumar, N., and Baum, B. (2016). Coupling changes in cell shape to chromosome segregation. Nat. Rev. Mol. Cell Biol. 17, 511-521. doi: 10.1038/ nrm.2016.75

Ranade, D., Koul, S., Thompson, J., Prasad, K. B., and Sengupta, K. (2017). Chromosomal aneuploidies induced upon Lamin B2 depletion are mislocalized in the interphase nucleus. Chromosoma 126, 223-244. doi: 10.1007/s00412016-0580-y

Rieder, C. L., and Alexander, S. P. (1990). Kinetochores are transported poleward along a single astral microtubule during chromosome attachment to the spindle in newt lung cells. J. Cell Biol. 110, 81-95. doi: 10.1083/jcb.110.1.81

Roberts, A. J., Kon, T., Knight, P. J., Sutoh, K., and Burgess, S. A. (2013). Functions and mechanics of dynein motor proteins. Nat. Rev. Mol. Cell Biol. 14, 713-726. doi: $10.1038 / \mathrm{nrm} 3667$

Roos, U. P. (1973). Light and electron microscopy of rat kangaroo cells in mitosis. I. Formation and breakdown of the mitotic apparatus. Chromosoma 40, 43-82. doi: 10.1007/bf00319836

Rosa, A., Vlassaks, E., Pichaud, F., and Baum, B. (2015). Ect2/Pbl acts via Rho and polarity proteins to direct the assembly of an isotropic actomyosin cortex upon mitotic entry. Dev. Cell 32, 604-616. doi: 10.1016/j.devcel.2015.01.012

Salina, D., Bodoor, K., Eckley, D. M., Schroer, T. A., Rattner, J. B., and Burke, B. (2002). Cytoplasmic dynein as a facilitator of nuclear envelope breakdown. Cell 108, 97-107. doi: 10.1016/s0092-8674(01)00628-6

Sato, A., Isaac, B., Phillips, C. M., Rillo, R., Carlton, P. M., Wynne, D. J., et al. (2009). Cytoskeletal forces span the nuclear envelope to coordinate meiotic chromosome pairing and synapsis. Cell 139, 907-919. doi: 10.1016/j.cell.2009. 10.039

Sawin, K. E., Leguellec, K., Philippe, M., and Mitchison, T. J. (1992). Mitotic spindle organization by a plus-end-directed microtubule motor. Nature 359, 540-543. doi: 10.1038/359540a0

Schreiner, S. M., Koo, P. K., Zhao, Y., Mochrie, S. G., and King, M. C. (2015). The tethering of chromatin to the nuclear envelope supports nuclear mechanics. Nat. Commun. 6:7159.

Silkworth, W. T., Nardi, I. K., Paul, R., Mogilner, A., and Cimini, D. (2012). Timing of centrosome separation is important for accurate chromosome segregation. Mol. Biol. Cell 23, 401-411. doi: 10.1091/mbc.e11-02-0095

Smith, E., Hegarat, N., Vesely, C., Roseboom, I., Larch, C., Streicher, H., et al. (2011). Differential control of Eg5-dependent centrosome separation by Plk1 and Cdk1. EMBO J. 30, 2233-2245. doi: 10.1038/emboj.2011.120

Smith, E. R., Capo-Chichi, C. D., and Xu, X. X. (2018). Defective nuclear lamina in aneuploidy and carcinogenesis. Front. Oncol. 8:529. doi: 10.3389/fonc.2018. 00529

Son, S., Kang, J. H., Oh, S., Kirschner, M. W., Mitchison, T. J., and Manalis, S. (2015). Resonant microchannel volume and mass measurements show that suspended cells swell during mitosis. J. Cell Biol. 211, 757-763. doi: 10.1083/ jcb. 201505058

Splinter, D., Tanenbaum, M. E., Lindqvist, A., Jaarsma, D., Flotho, A., Yu, K. L., et al. (2010). Bicaudal D2, dynein, and kinesin-1 associate with nuclear pore complexes and regulate centrosome and nuclear positioning during mitotic entry. PLoS Biol. 8:e1000350. doi: 10.1371/journal.pbio.1000350 
Starr, D. A., and Fridolfsson, H. N. (2010). Interactions between nuclei and the cytoskeleton are mediated by SUN-KASH nuclear-envelope bridges. Annu. Rev. Cell Dev. Biol. 26, 421-444. doi: 10.1146/annurev-cellbio-100109-104037

Stephens, A. D., Banigan, E. J., Adam, S. A., Goldman, R. D., and Marko, J. F. (2017). Chromatin and lamin A determine two different mechanical response regimes of the cell nucleus. Mol. Biol. Cell 28, 1984-1996. doi: 10.1091/mbc. e16-09-0653

Stewart, M. P., Helenius, J., Toyoda, Y., Ramanathan, S. P., Muller, D. J., and Hyman, A. A. (2011). Hydrostatic pressure and the actomyosin cortex drive mitotic cell rounding. Nature 469, 226-230. doi: 10.1038/nature09642

Stiff, T., Echegaray-Iturra, F. R., Pink, H. J., Herbert, A., Reyes-Aldasoro, C. C., and Hochegger, H. (2020). Prophase-specific perinuclear actin coordinates centrosome separation and positioning to ensure accurate chromosome segregation. Cell Rep. 31:107681. doi: 10.1016/j.celrep.2020.107681

Sun, M., Biggs, R., Hornick, J., and Marko, J. F. (2018). Condensin controls mitotic chromosome stiffness and stability without forming a structurally contiguous scaffold. Chromosome Res. 26, 277-295. doi: 10.1007/s10577-018-9584- 1

Sun, Z., Guo, S. S., and Fassler, R. (2016). Integrin-mediated mechanotransduction. J. Cell Biol. 215, 445-456. doi: 10.1083/jcb.201609037

Tanenbaum, M. E., and Medema, R. H. (2010). Mechanisms of centrosome separation and bipolar spindle assembly. Dev. Cell 19, 797-806. doi: 10.1016/j. devcel.2010.11.011

Thery, M., and Bornens, M. (2008). Get round and stiff for mitosis. HFSP J. 2, 65-71. doi: 10.2976/1.2895661

Thery, M., Jimenez-Dalmaroni, A., Racine, V., Bornens, M., and Julicher, F. (2007). Experimental and theoretical study of mitotic spindle orientation. Nature 447, 493-496. doi: 10.1038/nature05786

Thery, M., Racine, V., Pepin, A., Piel, M., Chen, Y., Sibarita, J. B., et al. (2005). The extracellular matrix guides the orientation of the cell division axis. Nat. Cell Biol. 7, 947-953. doi: 10.1038/ncb1307

Toyoshima, F., and Nishida, E. (2007). Integrin-mediated adhesion orients the spindle parallel to the substratum in an EB1- and myosin X-dependent manner. EMBO J. 26, 1487-1498. doi: 10.1038/sj.emboj.7601599

Tse, H. T., Weaver, W. M., and Di Carlo, D. (2012). Increased asymmetric and multi-daughter cell division in mechanically confined microenvironments. PLoS One 7:e38986. doi: 10.1371/journal.pone.0038986

Turgay, Y., Champion, L., Balazs, C., Held, M., Toso, A., Gerlich, D. W., et al. (2014). SUN proteins facilitate the removal of membranes from chromatin during nuclear envelope breakdown. J. Cell Biol. 204, 1099-1109. doi: 10.1083/ jcb. 201310116

Ungricht, R., and Kutay, U. (2017). Mechanisms and functions of nuclear envelope remodelling. Nat. Rev. Mol. Cell Biol. 18, 229-245. doi: 10.1038/nrm.2016.153

Uroz, M., Wistorf, S., Serra-Picamal, X., Conte, V., Sales-Pardo, M., Roca-Cusachs, P., et al. (2018). Regulation of cell cycle progression by cell-cell and cell-matrix forces. Nat. Cell Biol. 20, 646-654. doi: 10.1038/s41556-018-0107-2

van Heesbeen, R. G., Raaijmakers, J. A., Tanenbaum, M. E., and Medema, R. H. (2013). Nuclear envelope-associated dynein cooperates with Eg5 to drive prophase centrosome separation. Commun. Integr. Biol. 6:e23841. doi: 10.4161/ cib. 23841

van Steensel, B., and Belmont, A. S. (2017). Lamina-associated domains: links with chromosome architecture, heterochromatin, and gene repression. Cell 169, 780-791. doi: 10.1016/j.cell.2017.04.022
Verde, F., Dogterom, M., Stelzer, E., Karsenti, E., and Leibler, S. (1992). Control of microtubule dynamics and length by cyclin A- and cyclin B-dependent kinases in Xenopus egg extracts. J. Cell Biol. 118, 1097-1108. doi: 10.1083/jcb.118.5. 1097

Verde, F., Labbe, J. C., Doree, M., and Karsenti, E. (1990). Regulation of microtubule dynamics by cdc2 protein kinase in cell-free extracts of Xenopus eggs. Nature 343, 233-238. doi: 10.1038/343233a0

Versaevel, M., Braquenier, J. B., Riaz, M., Grevesse, T., Lantoine, J., and Gabriele, S. (2014). Super-resolution microscopy reveals LINC complex recruitment at nuclear indentation sites. Sci. Rep. 4:7362.

Versaevel, M., Grevesse, T., and Gabriele, S. (2012). Spatial coordination between cell and nuclear shape within micropatterned endothelial cells. Nat. Commun. 3:671.

Vianay, B., Senger, F., Alamos, S., Anjur-Dietrich, M., Bearce, E., Cheeseman, B., et al. (2018). Variation in traction forces during cell cycle progression. Biol. Cell 110, 91-96. doi: 10.1111/boc.201800006

Vitiello, E., Moreau, P., Nunes, V., Mettouchi, A., Maiato, H., Ferreira, J. G., et al. (2019). Acto-myosin force organization modulates centriole separation and PLK4 recruitment to ensure centriole fidelity. Nat. Commun. 10:52.

Whitehead, C. M., Winkfein, R. J., and Rattner, J. B. (1996). The relationship of HsEg5 and the actin cytoskeleton to centrosome separation. Cell Motil. Cytoskeleton 35, 298-308. doi: 10.1002/(sici)1097-0169(1996)35:4<298::aid$\mathrm{cm} 3>3.0 . \mathrm{co} ; 2-3$

Yu, J., Lei, K., Zhou, M., Craft, C. M., Xu, G., Xu, T., et al. (2011). KASH protein Syne-2/Nesprin-2 and SUN proteins SUN1/2 mediate nuclear migration during mammalian retinal development. Hum. Mol. Genet. 20, 1061-1073. doi: 10. 1093/hmg/ddq549

Zhai, Y., Kronebusch, P. J., Simon, P. M., and Borisy, G. G. (1996). Microtubule dynamics at the G2/M transition: abrupt breakdown of cytoplasmic microtubules at nuclear envelope breakdown and implications for spindle morphogenesis. J. Cell Biol. 135, 201-214. doi: 10.1083/jcb.135. 1.201

Zhang, X., Lei, K., Yuan, X., Wu, X., Zhuang, Y., Xu, T., et al. (2009). SUN1/2 and Syne/Nesprin-1/2 complexes connect centrosome to the nucleus during neurogenesis and neuronal migration in mice. Neuron 64, 173-187. doi: 10. 1016/j.neuron.2009.08.018

Zlotek-Zlotkiewicz, E., Monnier, S., Cappello, G., Le Berre, M., and Piel, M. (2015). Optical volume and mass measurements show that mammalian cells swell during mitosis. J. Cell Biol. 211, 765-774. doi: 10.1083/jcb.201505056

Conflict of Interest: The authors declare that the research was conducted in the absence of any commercial or financial relationships that could be construed as a potential conflict of interest.

Copyright (c) 2021 Dantas, Lima and Ferreira. This is an open-access article distributed under the terms of the Creative Commons Attribution License (CC BY). The use, distribution or reproduction in other forums is permitted, provided the original author(s) and the copyright owner(s) are credited and that the original publication in this journal is cited, in accordance with accepted academic practice. No use, distribution or reproduction is permitted which does not comply with these terms. 